\title{
$\mathrm{SNS}$ 를 통한 선거의 자유와 허위사실공표죄
}

\author{
이 주일*

\section{Through SNS and freedom of election Publicized criminal misrepresentation}

\author{
JU-IL Lee *
}

요 약

이 논문에서는 헌법재판소의 판결을 통하여 SNS를 통한 선거운동의 자유가 사실상 보장되었음에도 불구하고, 아직도 많은 부분 공직선거법상에서 선거운동의 자유를 제약하는 규정이 존재하여 이것이 앞으로의 선거에서 많은 법적인 문제를 야기할 가능성이 농후하다. 더욱이 그동안의 선거운동과는 차원이 다른 SNS를 통한 선거운동의 과 정에서, 무한확산의 가능성이 어느 시점보다 높아지고 있는 시점에서 SNS를 통한 선거운동의 자유와 공직선거법상 허위사실유포의 한계와 관련하여 많은 문제가 발생할 가능성이 높다. 이에 그동안의 공직선거법상 허위사실 유포 죄는 유포한 사실이 허위일 뿐만 아니라. 그 유포를 통하여 특정인을 낙선시키려는 목적이 있어야 성립하는 범죄로 규정되어 있음에도 이에 대한 엄격하게 해석하기 보다, 유포된 사실이 허위인가에 대하여 판단하는 형태로 법원의 판단이 이루어져 왔다. 따라서 이 법을 개정 또는 삭제하기 전에 엄격한 해석의 필요성에 대하여 논의하고자 하였 다. 입법론상 폐지하는 것이 바람직하지만, 우선 해석학을 통하여 문제점을 지적하였다. 첫째, 보호법익을 본죄의 취지 맞게 제한적으로 해석하고자 하였다. 둘째, 본죄가 목적범이기 때문에 목적범에서 목적은 본죄의 경우 엄격하 게 해석할 필요성을 주장하였다. 왜나하면 인터넷 공간에서 이른바 리트윗의 경우에는 팔로워들이 별 의미없이 행 해지는 경우도 많을 것이기 때문에 본죄로 처벌하는데 한계가 있을 것이 분명하다. 그리고 모처럼 헌법재판소에서 SNS를 통한 선거운동의 자유를 보장하고 있는 만큼, 우리나라에서 선거의 자유로운 소통의 장을 열어주는 의미에 서도 제한적 해석은 필요하다. 이는 표현의 자유를 높게 보장하게 될 것이고 이는 성숙한 시민사회로 가는 첩경이 될 것이기 때문이다.

- Keywords : 공직선거법, 소셜네트워크서비스, 흑색선전, 허위사실유포, 목적범

- 제1저자 : 이주일

- 투고일 : 2013. 1. 29, 심사일 : 2013. 2. 1, 게재확정일 : 2013. 2. 12

* 신라대학교 법경찰학부(Dept. of Law\& Police Science, Silla University) 


\begin{abstract}
In this paper, the Constitutional Court's ruling through the SNS was virtually guaranteed the freedom of election campaign through, though, still a large portion of campaign restrictions on public election law provisions exist to this forward in the election is likely to cause a lot of legal problems.

In this paper, the Constitutional Court's ruling through the SNS was virtually guaranteed the freedom of election campaign through, though, still a large portion of campaign restrictions on public election law provisions exist to this forward in the election is likely to cause a lot of legal problems. Moreover, in the mean time the campaign and which in the course of the election campaign through the SNS, the infinite potential of the growing point than any point spread from the SNS and freedom of election campaign through public election law with regard to the limitation of the diffusion of false facts, awards, a number of problems are likely to occur. You've been in this business and disseminate false guilt disparage precandidacy for true-false, as well. He should be able to reach a specific goal you want to defeat through the dissemination of information which is specified as a crime for this strictly for the fact that disseminate false, rather than to interpret it is the judgment of the Court in that judgment against have been made. Therefore, this strict interpretation of the law and the need to revise or delete before I would like to discuss about. The legislation would repeal the cull of Ron sang first of all point out the issue through analytics.

First, the purpose of the data protection Act provides limited interpretation to fit in this world of sin. Secondly, this sin is committed for the purpose of prevention, since the purpose of the objective in this case of sin and the need to interpret strictly. Why I am the Internet space in the case of so-called tweets from followers, this means in some cases done without a lot of the stars because of this, there will be a limit to the punishment of sin, this is obvious. And, in the long-awaited Constitutional Court ensures the freedom of election campaign through SNS and free election in the country, even in the limited sense interpretation opens the chapter of communication is needed. This ensured the freedom of expression will be highly this is a mature civil society that will be imperative.
\end{abstract}

- Keywords : Public Election law, Propaganda, Spreading false information, SNS, The purpose crime

\section{I. 서 론}

스마트폰의 보급이 확대되면서 사이버상의 세상 다시 말해

서 소셜네트워크에 기반한 SNS(Boyd, D. M. \& Ellison,

N. B. (2007). Social Network Sites: Definition,
History, and Scholarship. Journal of Computer-Mediated Communication, 13, PP210)의 확산은 사회문화적인 변화와 함께 선거에서도 중요한 영향을 미치는 도구로 사용되고 있다. SNS를 선점하는 자가 선거에 서 승리한다는 것이 아주 중요한 공식처럼 변해하고 있는 세 상이 되었다. 최근 치루어진 19 대 국회의원 총선거에서도 많 
은 영향력을 끼쳤을 것이라는 점에 대하여 부정하는 사람은 아마도 많지 않을 것이다. 물론 사이버 선거운동이 선거를 치 르는 당사자들에게 부정적인 영향을 주었는가? 긍적적인 영 향을 주었는가?는 별론하고, $\mathrm{SNS}$ 를 통한 선거운동의 중요 성은 앞으로도 대단히 중요한 역할을 수행할 것인 것 만큼은 자명하다 할 것이다. 사이버공간에서 이루어지는 선거운동을 통해 순기능과 역기능에 대한 것을 소개하지 않아도 좋을 만 큼 산재하여 있다. 법제도적으로 유념해야 할 것은 쇼셜네트 워크의 발전속도를 법제도 따라가지 못하여 사람들간의 의사 소통과 정보의 공유, 그리고 보이지 않는 인적네크워크를 형 성하는데 기여하고 있는 이 시스템이 자칫 역기능적면을 양산 하는 도구로 전락하게 될 것이다. 따라서 이러한 분야에 대한 법제도적 보완이 필요한 시점이고 이에 대한 연구의 중요성이 강조되고 있다. 주지하는 바와 같이 사이버명예훼손이나 모욕 죄와 같은 것에 대한 논의가 있었고, 사이버 명예훼손에 대한 논의들이 있어왔다. 인터넷상에서 명예훼손이나 모욕이 발생 한 경우에 형법 제 33 장의 명예에 관한 죄 및 정보통신망 이용 촉진 및 정보보호 등에 관한 법률 제70조 등에 의한 처벌이 가능한 실정이다. SNS가 지는 정보의 생산능력, 신속성과 그 파급력은 정보의 수령자에서 정보의 적극적인 확대 재생산이 가능한 기술과 환경의 발달로 인하여 기존의 대중 매체보다 도 훨씬더 여론을 형성하는데 큰 영향력을 행사할 것이 분명 해지고 있다. 특히, 올해는 총선과 대선이라는 중대한 정치적 변혁의 시대의 도래를 맞이하는 시점에서 공직선거상의 SNS 의 이용빈도는 어느 때보다 다양하고 정치적 의견에 대한 소 통 다양하게 이루어질 것이다. (실제로 19 대 국회의원 선거를 위한 정당의 공천과정에서 소위 '트위터지수'를 공천에 반영한 예도 있었다; 백일현, “한나라당 “트위터지수'공천에 반영”, 중 앙일보, 2012. 01.11) 공직선거와 관련하여 SNS를 통한 선 거운동의 자유가 허용된 상황에서 여전히 문제가 되는 선거사 범의 유형에는 금품선거사범, 흑색선전사범, 선거폭력, 사위 투표행위의 중대 선거범죄유형은 존재한다. 이 중에서 SNS 선거운동의 자유와 가장 문제가 되는 것은 소위 흑색선전사범 이 문제된다. 따라서 공직선거법상 이 문제의 해석및 개선방 안에 대하여 논의는 중요하다고 생각된다.

\section{SNS선거범죄}

\section{SNS를 이용한 흑색선전사범의 문제}

$\mathrm{SNS}$ 를 이용한 선거운동 허용되면서 가장 많은 문제가 되
는 것은 다름 아닌 이른바 흑색선전사범의 증가가 문제되고 있다고 할 것이다. 실제로 SNS를 통한 허위사실의 유포는 개 인의 인격적 법익인 명예훼손이나 신용훼손, 모욕죄의 성립과 관련하여 많은 논의가 있고, 사회적 문제가 되고 있지만, 이 는 개인적 법익의 보호에 관한 문제인 반면, 공직선거법상 허 위사실을 공포하여 선거운동을 함으로써 선거의 결과에 중대 한 영향을 미쳐 궁극적으로 우리 나라 정치발전에 저해를 초 래할 가능성이 높다 할 것이다. 따라서 이 문제는 다른 SNS 의 역기능보다 심각하다고 생각된다. 그렇기 때문에 역설적으 로 형사법의 역할이 중요하다고 생각되고, 더욱 명확한 판단 기준을 제시하는 것이 필요한 시점이 아닌가 생각된다. 이 문제는 더욱이 2011년 12월 29일 헌법재판소가 트위터를 비롯한 소셜네트워크서비스(SNS) 등을 이용한 사전선거운동 을 금지하는 것은 한정위헌이라고 결정하면서 더욱 부각되었 다. 헌법재판소는 "인터넷은 누구나 손쉽게 접근 가능한 매체 이고, 이를 이용하는 비용이 거의 발생하지 않거나 또는 적어 도 상대적으로 매우 저렴해 선거운동비용을 획기적으로 낮출 수 있는 정치공간으로 평가받고 있다"며 선거일전 180 일부터 선거일까지 선거에 영향을 미치게 하기 위하여 정당 또는 후 보자를 지지·추천하거나 반대하는 내용이 포함되어 있거나 정당의 명칭 또는 후보자의 성명을 나타내는 문서 · 도화의 배 부·게시 등을 금지하고 처벌하는 공직선거법 제 93 조 제 1 항 및 제 255 조 제 2 항 제 5 호 중 제 93 조 제 1 항의 각 '기타 이와 유사한 것'부분에 '정보통신망을 이용하여 인터넷 홈페이지 또 는 그 게시판 - 대화방 등에 글이나 동영상 등 정보를 게시하 거나 전자우편을 전송하는 방법이 포함된다고 해석한다면, 과잉금지원칙에 위배하여 정치적 표현의 자유 내지 선거운동 의자유를 침해하고한다고 하였다. (헌법재판소 2011. 12. 29. 자 2007헌마 1001 결정)이를 계기로 선거운동의 SNS를 통한 선거운동의 자유화를 인정하게 되었다. 따라서 공직선거 법 제 250 조의 허위사실 공표죄의 의미는 더욱 중요한 기능을 담당하게 되었다고 할 것이다. 따라서 이를 잘 살펴서 SNS상 에서 선거운동을 통한 표현의 자유를 침해하지 않고, 동시에 허위사실 공표죄와 상충하지 않는 자유로운 선거운동의 지평 을 열기 위해서 본죄의 검토가 반드시 있어야 한다고 본다. 특히 헌법재판소의 판결에서 반대의견에서 밝히고 있는 바와 같이 허위사실공표나 비방 등을 처벌하는 공직선거법 제 110 조,제 250 조, 제 251 조, 선거관리위원회의 시정조치라든가 사이버선거부정감시단 등 선거관리감독을 위한 제도적 장치 만으로 위와 같은 폐해를 막기에 부족하다는 지적을 하면서 반대의견을 제시한 것에 주목할 필요가 있다. (재판관 이동흡, 재판관 박한철의 반대의견(헌법재판소 2011. 12. 29. 자 
2007헌마1001 결정)） SNS를 통한 선거운동의 자유가 보 장되었지만, 여전히 공직선거법 제 250 조에 의하여 선거운동 의 자유는 제한을 받고 있다. 19 대 국회의원 선거에서도 인터 넷을 통한 선거법위반사례는 대폭 줄어든 것으로 파악되었지 만, 공직선거법상 처벌이 가능한 후보자 비방죄와 흑색선전사 범은 여전히 줄지 않았다, (이재진기사,"인터넷 선거운동 허용 이후 선거법 위반 성적표는?", 미디어오늘, 2012. 4.26일자 신문에서 참조) 따라서 $\mathrm{SNS}$ 를 통한 선거운동의 자유가 허용 된 시점에서 공직선거법 제 250 조의 허위실공표죄의 개선이나 해석의 명확성을 위해 검토하고자 한다.

\section{2. 공직선거법상 흑색선전사범}

\section{1) 허위사실공표죄(공직선거법 제250조)}

당선되게 하거나 당선되지 못하게 하는 행위를 선거운동이 라고 하고, 공직선거법 제 58 조 제 2 항에서 누구든지 이 법 또 는 다른 법률의 규정에 의하여 금지 또는 제한되는 경우를 제 외하고는 자유롭게 선거운동을 할 수 있다고 규정하고 있다. 이법에서 금지하고 있는 대표적인 내용이, 공직선거법 제 250조에서 규정한 허위사실 공표죄인데, 그 내용은 '당선되거 나 되게 할 목적, 당선되지 못하게할 목적으로 후보자, 또는 후보자가 되려는 자에게 유리 또는 불리하게 후보자, 그의 배 우자 또는 직계존·비속이나 형제자매의 출생지·신분·직업·경 력등-재산·인격·행위·소속단체 등에 관하여 허위의 사실을 공 표하는 경우를 선거사범으로 처벌하고 있다. 이에 대하여 SNS를 통한 선거운동의 자유가 허용되면서, 본조의 성립범 위를 명확하게 하는 것이 중요한 문제가 되었다고 판단된다.

\section{2) 목적범에 대한 검토}

공직선거법 제 250 조의 구성요건을 살펴보면 '당선되거나 되게할 목적 혹은 당선되지 못하게 할 목적으로 '후보자를 유 리하게 하거나, 불리하게할 허위의 사실을 공포한 자와 허위 의 사실을 게재한 선전문서를 배포할 목적으로 소지한자를 벌 하는 규정을 두고 있고, 목적범의 형태로 규정하고 있다. 목 적범은 행위자의 범죄사실에 대한 인식인 고의의 존재 이외 별도의 초과주관적 구성요건 요소로서의 목적이 존재하여야 성립하는 범죄이다. 행위자가 구성요건의 객관적 요소인 고의 를 인식하는 이외 목적이라는 초과주관적 구서요건 요소를 부 가된 경우에 법익침해의 위험성이 증대되거나 특수한 위험성 이 발현되는 범죄유형을 의미한다. 다시 말해서 허위의 사실 을 공포한다는 고의만으로 부족하고, 이에 더하여 행위자의 추가적인 심리현상이 있어야 비로소 법익침해의 불법성을 인 정하게 된다.(이용식, “고의와 목적에 관하여", 현대사법학,
1996, 393면 참조) 형법 제 152 조 제 2 항의 모해위증죄에 있 어서 '모해할 목적'이란 피고인·피의자 또는 징계혐의자를 불 리하게 할 목적을 말하고 이러한 목적이 있어야 비로소 단순 위증죄에 비하여 위증죄의 보호법익인 국가 사법기능을 위태 롭게 하닌 이외에 피고인,피의자 또는 징계혐의자의 생명이나 신체, 재산 등 개인적 법익에 대하여도 고도의 위험을 가중하 기 때문에 가중처벌되는 것이다. (정영일, “목적범", 고시계, 2001/11, 64면 이하)

\section{3) 목적범의 유형에 따른 검토}

객관적 구성요건요소인 행위가 초과주관적 구성요건요소 인 목적을 실현하기 위한 수단이 되는 경우로서 행위의 동기 나 목적이 초과주관적 구성요건 요소인 목적과 일치하는 경우 로 단절된 결과범이라고 하고, 객관적 구성요건요소인 행위의 수행이 있는 것만으로는 구성요건해당성이 바로 인정될 수 없 고 소정의 목적의 존재에 대한 별도의 직,간접적인 입증이 요 구되는 경우를 불완전한 이행위범이라고 하여 구분하고 있 다. (Jescheck/Weigend, Lehrbuch des Strafrecht AT. 5. Aufl., 1996, S. 319) 그래서 전자를 수단범, 후자를 준 비범이라고 부르는 견해도 있다. (김대휘, “국가보안법 제7조 1 항 및 제5항의 해석기준”, 형사판례연구 I, 1993, 229면) 이러한 구분의 실익은 목적범에 대하여 목적이 인정되려면 어 느정도의 인식이 필요한가를 결정하기 위하여 의미있는 구별 이 되고 있다. 물론 이에 대하여 반대의 견해가 있을 수 있다. 그렇지만 공직선거법 250 조의 허위사실공표죄가 목적범으로 되어 있고, 그렇다면 이에 대한 검토가 필수적이라 할 수 있 고, 목적범을 두가지로 구분하고, 과연 본죄를 어떤 유형에 편입시킬것인가에 대한 결정을 하는 것이 목적범의 목적의 인 식정도를 가늠하는 중요한 단서가 될 것이라고 판단된다. 다 시 말해서 250조의 경우에 적어도 SNS를 통한 소통의 파급 력등을 감안하더라도 이 문제를 정확하게 할 필요가 있다. 목 적범의 유형에 따른 분류를 논의하는 이유는 다름 아닌 목적 범에서 목적이 확정적이야 하는가? 아니면 미필적으로 인식 할 수 있을 정도의 목적만 있으면 되는가의 문제를 분명하게 하는 것이 필요하다고 본다. 우리 법원의 입장은 목적범에서 의 목적에 대한 인식은 미필적으로 인식하고 있으면 목적범의 목적이 인정된다고 본다. 그러나 사실상 이러한 목적범에서 목적은 엄밀하게 말하면 내심의 의사이기 때문에 공직선거법 위반 여부를 다투기 위해서는 범죄의 목적이 있었는지 여부에 대하여 실질적으로 판단하기 어려움이 있고, 따라서 법원도 이러한 행위자의 의도를 분명하게 파악하기 어렵다는 점을 스 스로 자인하면서 미필적으로 인식하면 족하다는 입장을 견지 하고 있다.(대법원(전원합의체), 1992. 3. 31.선고 90도 
2033판결) 목적범이 성립하기 위해서 주관적 구성요건인 고 의 이외에 다른 목적 실현을 의욕하고 있어야 하고, 고의를 초과하는 내심의 목적이 있어야 한다. 따라서 목적범에서 목 적의 내용을 확정적으로 인식하여야 할 것이다. SNS를 통한 엄청한 선거운동에 관한 사이버상에서 생산되어진 정보들을 별다른 의심없이 그것을 재생산하는 것이 너무나도 자유로워 진 환경에서 본 범죄의 목적성을 확정적으로 인식하지 않는다 면 SNS를 통한 선거운동의 자유가 보장되어도 위축될 수 밖 에 없을 것이고, 누군가의 트윗을 받아 무한 리트윗하는 등의 행위를 하는 것이 너무도 자유로운 세상에서 선거운동의 자유 가 제한될 가능성이 농후하다. 따라서 법원은 본범죄의 판단 에서 목적을 확정적으로 인식한 경우에 본죄의 목적이 성립하 는 것으로 해석하는 것이 바람직할 것이다. 그렇게 해석하지 않는다면 부지불식간에 자신의 SNS에서 발생된 수많은 선거 와 관련된 행위로 인하여 공직선거법위반의 죄로 처벌이 오히 려 확대될 가능성이 농후하다.

\section{4) 허위사실의 내용에 대한 검토}

당선시키거나 낙선시킬 목적으로 허위의 사실을 공표한 경 우에 본죄의 구성요건에 해당하는 것으로 규정되어 있다. 허 위의 사실이란 주지하는 바와 같이 실제의 객관적인 사실과 다른 사실을 의미한다. 이에 대하여 우리 법원은 "피고인이 간 접적이고 우회적인 표현 방식을 통하여 사실 등의 존재를 임 시하여 전체적으로 볼 때 사회적 가치 내지 평가를 그르치게 할 가능성이 있을 정도"가 되면 허위사실이 될 수 있고, 후보 자의 공직 적격성을 심사하는 것이 자유롭게 허용되어야고 한 다면서도 “후보자의 비리 등에 관한 의혹의 제기는 비록 그것 이 공직 적격 여부의 검증을 위한 것이라도 무제한 허용될 수 는 없고 그러한 의혹이 진실인 것으로 믿을 만한 상당한 이유 가 있는 경우에 한하여 허용되어야 하며, 그러한 상당한 이유 가 있는 경우"에만 허용된다고 하여 민주주의 정치제도하에 서 표현의 자유는 가장 기초적인 기본권임에도 불구하고 선거 과정에서 이러한 입장을 법원이 견지하는 이상 대단히 이러한 기본권의 행사가 제한받을 가능성이 있다. (대법원 2011.12.22. 선고 2008도11847 판결) 법원은 간접적 우회 적으로 문제를 제기한 경우에도 유권자의 선택을 오도하는 중 대한 결과를 야기하고, 이는 공익에 현저히 반한다는 입장이 다. 이러한 규정이 그대로 존치하고, 이 규정의 해석을 둘러 싸고 법원의 입장에 변화가 없다면, 모처럼 조성된 SNS등을 통한 선거운동의 자유는 대단히 위축될 가능성이 농후해졌다. 허위사실의 유포가 공익을 해할 수 있다는 판단, 그것도 상당 성을 국가가 판단하는 것은 민주적 정치제도 하에서 바람직할 것이라고 할 수 없다. 헌법재판소에서 인터넷실명확인에 대한
위헌 결정을 한 것에 부합하여 공직선거법상 실명확인을 폐지 하는 공직선거법 개정 의견을 제출하면서도 여전히 허위사실 공표죄는 그대로 두고 있다. 유권자의 자유로운 판단을 해하 고 자유롭고 공정한 선거를 위협하는 허위사실이란 과연 어떤 것이 있을 수 있을까에 대한 엄격한 판단이 필요한 시점이 되 었다. 열린사회에서 공정선거에 중대한 영향을 미치는 허위사 실의 유포가 가능한가에 대하여 의견이 분분할 수 있을 것이 다. 의견이 분분할 수 있다는 것은 죄형법정주의 명확성원칙 에 반할 수 있다. 따라서 사실상 $100 \%$ 개방된 구조인 SNS 등 인터넷을 통한 선거운동에서 발생하는 수많은 허위와 진실 을 규명하는 것이 법리적으로 가능한 것인가에 대하여 고민을 해야 한다고 본다. 전통적인 언론을 통한 여론형성과정에서 국민들은 단순히 여론에 휩쓸리는 대상에 불과하였지만, SNS가 확대되면서 이슈의 생산과 유통에 참여하고 이슈를 선도하는 역할을 하는 것으로 평가한 연구결과를 보더라도 공직선법상의 본조에 대한 개선이 필요한 시점이 되었다고 판 단된다. (박상호, "SNS의 여론형성과정과 참여행태에 관한 고 찰", 한국언론정보학보 통권 58호, 2012.5. 55면 이하 참 조)

우리 법원의 재판과정에서 공직선거법 제 250 조 제 2 항의허 위사실 공표죄에 대한 판단을 살펴보면 첫째, 대통령 후보로 출마한 다른 당 소속의 국회의원이 간접적이고, 우회적인 표 현방식을 통하여 허위사실을 공표한 경우에도 그것이 당사자 에 대한 사회적 평가를 그르치게 할 가능성이 있을 정도의 구 체성을 가질 수 있다고 하고, 간접적, 우회적 표현일 뿐 사실 의 적시가 없었다는 점에 대하여도 주장들의 전체적 의미를 보고 대통령 후보자에 대한 사회적 가치나 평가를 그르치게 할 가능성이있을 정도고 하여 본죄를 인정하고 있다. 뿐만 아 니라 공직선거법상 허위사실공표죄가 성립하는 경우 그 행위 가 공공의 이익을 위한 것이라고 하여도 위법성이 조각되지 않는다는 입장을 취하고 있다. (대법원 2011.12.22. 선고 2008도11847 판결; 대법원 2009. 5.28. 선고 2009도 2194 공직선거법위반;대법원 2009. 5.28. 선고 2009도 2194 공직선거법위반) 반면 특정 동문회가 특정후보를 공개 지지한다는 취지의 허위의 성명서를 작성하여 언론사에 보도 자료로 제공한 행위는 공직선거법상 허위사실공표에 해당하 지 않는다고 하였다. 그리고 중앙선거관리위원회 인터넷 홈페 이지 후보자 정보란'에 경력과 소속단체 등에 관하여 허위의 사실을 공표하게 한 행위가 공직선거법 제 250 조 제 1 항에서 규정한 '기타의 방법'에 의한 허위사실 공표에 해당한다하여 법원의 입장은 본죄를 해석함에 있어서 허위사실인가 아닌가 에 대하여 집중적으로 규명하고, 공표인가 아닌가에 대하여 
기재한 사실이 무엇인가에 대한 검토, 자신이 허위의 사실을 공표하면서 인식이 있다고 볼 것인가, 단순한 의혹제기에 불 과한가 등의 문제만을 논의하고 있다. 이는 우리 법원은 이 문제에 대하여 허위의 사실인가 아닌가에 대한 입장을 견지하 여, 그것이 실질적으로 개인의 명예를 실추시킬 뿐만 아니라 선거의 공정성을 해칠 목적이 있었는가에 대한 입장은 논의하 지 않는다. 그것은 아마도 이런 허위사실을 공포하는 것에 당 선 혹은 낙선의 목적이 미필적으로 존재한다고 보는 기존의 입장을 견지하고 있다고 판단된다. 법원의 판례를 보면 이는 특정 정당이나 선거에 직접적인 연관이 있는 사람들에게 대체 로 엄격하게 적용하는 입장이라고 생각된다. 문제는 이러한 것들이 기존의 언론 방식이 아닌 누군가 그런 사실을 공표하 고, 이를 SNS를 통하여 급속하게 펴져 나가게 된다면 이 문 제를 지금의 문제 해결 방식으로는 해결하기 용이하지 않을 것이 자명하기 때문에 이부분에 대한 보다 정밀한 논의가 필 요하다고 하지 않을 수 없다. SNS를 통한 선거운동의 자유가 사실상 인정된 상황에서 공직선거법상 허위사실공표죄의 문 제는 엄격한 해석의 방법이나 법의 개선이 없이는 남용의 가 능성이 높아질 수 밖에 없을 것이 자명하다.

\section{5) 보호법익에 대한 검토}

민주사회에서 선거의 공정을 위한 형법의 임무는 중요하고 근본적인 임무라고 할 수 있다. SNS를 통한 선거운동이 자유 가 사실상 보장된 사정하에서 SNS를 통해 무한 확대 재생산 되는 무수한 사실들의 진위여부를 형법의 조기 투입을 통하여 해결하려는 태도는 지양되어야 한다고 생각된다. 복잡하고 다 양한 욕구들이 무한적으로 분출되는 상황에서 선거의 공정성 의 욕구는 더욱 높아질 것이다. 무엇을 보호가치로 삼을 것 인가에 대한 논의를 하는 것이 더욱 의미있는 이유가 된다고 본다. SNS를 통한 선거운동의 자유가 보장된 만큼 공정한 선 거를 달성하려는 국가적 임무는 더욱 강해질 것이고, 이러한 상황은 마치 라우 $(\mathrm{Lau})$ 가 지적하고 있는 것처럼 지금까지와 는 다른 새로운 위험의 형태롤 보이면서 그 형태와 범위를 비 교하는 것이 어려운 지경이 될 수 있을 것이 다. (ChristophLau, Gesellschaftliche Auseinandersetzungen um Definition von Risiken, Sozial Welt, 1989$, S. $415 \mathrm{ff})$ 본죄의 보호법익에 대하여 논이가 필요한 이유이다. 자신의 의사를 표시하는 경우 과거에는 당사자와 관련된 몇몇의 사람들에게 국한된 행위로 사실상 다른 사람들 에게 조직적으로 간섭하거나 사회적으로 가치있는 것으로 받 아들여 지지 않았기 때문에 공적인 영역에서 통제할 대상이 된다고 볼 수 없었을 것이다. 그러나 SNS를 통한 의사의 표 현은 주로 사적인 영역에 머무르지 않고 무한히 전파될 개연
성인 농후해 졌고, 행위단계에서 부분적인 역할을 하는 정도 에 그칠 수 있었던 불법이 전반적인 규범침해로 이어질 수 있 는 사정이 되었다는 점에 주목할 필요가 있다. 개인의 명예와 선거의 공정이라는 법익을 보호법익으로 하는데 이에 대한 논 의가 필요하다. 본조의 법익을 개인의 명예를 법익으로 한다 는 것은 불특정의 사람들 속에서 표현한 사실에 범죄의 의사 가 있다고 한다면 그러한 외적인 태도를 통한 표출만으로 법 적인 평온이 침해되고, 이는 피해자와의 관계속에서 이해한다 면 규범타당성을 침해할 기초적인 행위를 하였다는 이유로 처 벌 받게 되는 문제가 발생할 수 있다는 점을 생각해 봐야 한 다. 이는 마치 고해성사를 통하여 신부의 면전에서 행한 발언 이 SNS를 타고 무한 전파 될 가능성이 있다면 이 또한 처벌 의 대상이 될 수 있다는 문제를 야기할 수 있다. 부분적인 역 할이 쉽게 주된 역할로 변화시킬 가능성이 높아진 SNS의 역 할에 비추어 볼 때 국가적 간섭을 확대하는 결과를 낳게 될 수 있다는 점에서 이 문제에 대한 것을 논의하고, 개인의 명 예는 이미 공직선거법이 아니라 형법상 신용훼손이나 명예훼 손 등으로 처벌 가능한 부분이기 때문에 공직선거법상 허위사 실공표죄의 보호법익에 개인적 명예를 포함시키는 것은 규범 의 타당성만을 강조하여 국가의 불필요한 간섭을 확대하게 될 것이고, 이는 형법의 보충성 원칙에도 부합한다고 할 수 없다. 우리 법원의 판례를 살펴보아도 판단에는 피해자의 명예를 주 된 보호가치로 삼았다는 인식을 지울 수 없고, 선거의 공정성 이라는 것에 대하여 정의하기 어렵다는 이유가 있어서 인지는 알 수 없으나, 주된 판단의 근거로 삼고 있다고 볼 수 있다. 사실 우리나라에서 법익에 대한 논의를 하는 것은 형사입법자 들에게서 무시되고 있다고 해도 과언은 아니다. (이점은 이미 독일에서도 논의된 바가 있다.Claus Roxin, Zur Entwicklung der Kriminalpolitik seit den AlternativEntwürfen, JA 1980,S.545ff) 다만, 법해석론에 있어서 보호법익을 분명히 하여 불법을 개별화하는 토대를 제공할 수 있다고 본다. 형법을 통한 처벌의 한계를 분명히 하는 것은 국가 형벌권의 남용으로부터 시민의 자유와 권리를 보장하려 는 근대 법치국가의 사상에도 부합한다고 본다. 따라서 입법 론자들의 입법의 논의과정에서 비록 법익에 대한 논의가 충분 하지 않았다고 하여도 해석론에 의하여 보호법익을 필요최소 한으로 해석함으로서 자유로운 선거풍토를 마련하는 계기도 될 것이라고 생각된다. 공직선거법상 허위사실공표죄의 보호 법익을 지금처럼 개인의명예와 선거의 공정성을 모두 포함하 게 된다면 형법의 역할은 확대될 것이 자명하고 공직선거법상 허위사실공표죄로 처벌해야하는 불법과 다른 영역에서 처벌 하거나 규제해야 하는 불법의 구별이 어렵게 될 것이고, 이로 
인하여 비판을 면하기 어려울 것이다. 그리고 헌법재판소에서 SNS를 통한 사실상의 선거운동의 자유를 보장한 재판소결정 의 본질적인 취지를 잘 살리리 못하는 결과가 될 것이다. 따 라서 공직선거법상 허위사실공표죄의 보호법익은 선거의 공 정성이라는 것으로 제한적으로 해석하는 것이 타당하다 할 것 이다. 보호법익을 제한적으로 해석하지 않는다면 형법의 보호 가치는 그 영역의 확대를 초래할 것이고 이는 형법의 역할에 대한 위기가 초래될 것이고 환경의 변화에서 비롯된 자유로운 선거풍토를 위축시켜 민주주의의 발전을 저해하는데 형법이 부정적인 역할을 하게 될 것이다. 허위사실의 유포를 통하여 유포자가 획득하려는 목적이 있어야 성립하는 범죄임이 명백 함에도 허위사실 유포죄는 허위사실이가 아닌가에 초점을 두 어 평가하고, 이를 통하여 특정인의 명예를 보호하려는 것은 형법상의 명예훼손죄의 구성요건과 상충하는 문제를 해결하기 어렵다고 판단된다. 사회적 명예를 보호하는 것은 현행 형법하 에서 얼마든지 가능하다. 즉 타인의 명예를 훼손하는 요건이 갖추어 진다면 형법상 명예훼손죄의 성립을 논하면 된다. 공직 선거법상의 문제는 개인의 명예보다는 선거의 공정성이라는 공적인 기능이 더욱 높이 평가되고 보호되어야 할 가치라고 할 것이다. 더욱이 공직선거법상 처벌을 받게 되는 경우 피선거 권의 제한이라는 중대한 결과를 발생시킬 수 있다는 점에서 보 호법익에 대한 엄격한 해석도 필요하다 할 것이다.

\section{III. 결 론}

우리 헌법재판소가 SNS를 통한 선거운동의 자유가 보장 되었다. 그것은 놀라운 사회의 변화를 기존의 틀에서 제한하 는 것이 사실상 불가능하다는 점을 인정한 것이라 본다. 그럼 에도 현행 공직선거법에서는 선거의 자유를 과도하게 통제하 는 수단이 여전히 존재하고, 그 중 대표적인 것이 허위사실유 포죄라고 생각된다. 이런 이유에서 기존의 조항에 대하여 엄 격한 해석을 통하여 이를 제한적으로 적용할 필요가 크고, 궁 극적으로는 이 규정이 개정 또는 폐지되는 것이 바람직하다고 생각된다. 허위의 사실을 통하여 특정인의 명예를 훼손하거 나, 부당한 이득을 획득한 경우에 그것에 대한 민사 혹은 형 사상의 제재는 이미 존재한다. 문제는 공직선거법상의 본조는 이러한 것을 뛰어넘어 선거의 공정성이라는 공익적 필요가 크 고, 그 허위사실의 유포를 통하여 선거의 승리 또는 패배에 기여할 만한 목적이 명백한 경우만을 제한적으로 해석하여 적 용하는 것이 SNS를 통한 선거운동의 자유를 보장하고, 이는 궁극적으로 표현의 자유에 대한 보호를 강화하는 길이 될 것 이다. 우리는 역사적으로 이미 표현의 자유를 국가권력에 의
하여 통제하였을 때 우리 정부가 어떠한 길을 걸어왔는지 너 무도 잘 알고 있지 않은가? 열린사회에서 비판적 사고를 통제 한다면 우리 사회는 성숙한 시민사회라고 말하기 어려울 것이 다. 앞에서 강조하였지만, 표현의 자유를 위축시킨 결과로 초 래된 해악은 자유민주주의 국가의 발전을 저해하고, 민주적 선거풍토를 막는 것으로 헌법 37 조 2항에서 말하는 과잉금지 원칙에 반하고, 형법상 보충성의 원칙에도 반한다고 하지 않 을 수 없다. 더욱이 선거의 공정성이라는 보호법익을 해치는 허위사실이라는 것이 과연 객관적이고 공익적이라고 볼 수 있 는지도 의무의 여지가 있다. 객관적이고 검증가능성이 높은 자연과학의 영역에서도 진실과 허위는 그 시대적, 정치적 배 경에 따라서 호도되기도 한 것을 보면 어디까지가 허위이고, 어디까지가 진신인가를 규범적 잣대로 전단하는 것은 더욱 어 려운 일이다. 이는 죄형법정주의 명확성의 원칙에도 위배될 가능성이 높다. 이는 국가기관에서 자의적으로 법해석을 하 고, 재량권의 범위를 불명하게 할 소지가 농후하기 때문에 더 더욱 그러하다. 보충성 원칙은 형법을 통한 금지를 필요최소 한으로 하라는 것이지 보호를 약화시킬 수 있다고 해석되어서 는 안된다. 설령 그것이 명백한 허위라고 하여도 그것은 시민 의 문화로 극복되어야 할 것이다. 이를 국가가 통제하는 방식 으로는 과거의 작은 영역에서 가능할지는 모르지만, 지금처럼 온세상이 열려진 상황에서는 현실적으로 불가능하고, 이는 법 규범의 신뢰성을 더욱 저하시키는 결과만을 초래할 가능성이 크다. 그럼에도 현행 규정이 존재하기 때문에 몇가지 제안을 하면서 이글을 마무리 하고자 한다.

첫째, 공직선거법상 허위사실 유포죄에서 보호하는 법익을 무엇으로 볼 것인가에 대하여 지금처럼 개인의 명예와 동시에 선거의 공정성이라는 2 중적 법익을 인정할 것이 아니라, 선거 의 공정성 만을 보호법익으로 해석하는 것이 제한적 해석을 위해 바람직하다.

둘째, 본죄는 허위사실을 유포한 것만으로 성립하는 것이 아니고, 이를 유포하면서 후보자를 낙선시키려는 목적이 있어 야만 성립하는 목적범이다. 그러나 지금까지 목적범의 목적은 명확하여야 하는가 아니면 미필적이어도 되는가에 대하여 본 죄와 관련하여 논의가 없었다. 따라서 본죄가 성립되어 처벌 된 경우 다른 형벌에 의한 처벌과 달리 피선거권이 제한되는 2 중적인 기본권의 제한이 가해질 수 있기 때문에 본죄의 목적 을 미필적인 목적으로 해석하여서는 안되고, 엄격하게 해석하 여야 할 것이다.

우선적으로 이러한 해석 방법을 국가기관이 취하게 된다 면, SNS라는 열린사회의 첨단 도구를 이용하여 의사소통의 공간에 대한 제약을 없애버린 지금의 사회에서 선거운동의 자 
유를 보장하는 것은 표현의 자유를 보장하는 것이고, 이는 표 현의 자유를 억압하는 국가가 더욱 부패한 국가였다는 역사적 오명 또한 정리할 수 있는 계기를 만들 수 있을 것이다. 궁극 적으로 국가와 정치인들은 $\mathrm{SNS}$ 의 공간을 단순히 선거 홍보 를 위한 공간이 아니라 선거에서 진정한 소통의 공간으로 조 성하기 위한 노력을 하는 것이 바람직하다. 우리나라처럼 소 위 인터넷 여론과 실제 여론의 차이가 많은 나라가 없다고 한 다. 그것은 그동안의 권위주의 정부시절에 통제를 통하여 자 신들을 스스로 감시하는 습관을 길러버린 탓일 수 도 있다고 생각된다. 우리는 우리의 의사를 표명하면서 항상 누군가의 공격에 대한 방어적인 생각을 먼저하게 된다. 많은 인터넷 훌 리건들이 존재한다는 점도 사실이다. 그러나 흙탕물을 맑게 만들기 위해서는 물을 막는 것이 아니라 더욱 많은 물이 흘러 가게 하는 것이 바람직하다. 그리고 인터넷 공간에서 단장취 의(斷章取義)하는 형태의 트윗과 리트윗이 난무하는 실정을 기존의 법질서로 통제하기는 불가능하다고 판단된다. 그리고 그러한 해석태도를 법의 잣대로 통제하는 것도 더더욱 불가능 하다고 판단된다. 다만 개인적으로는 파워트위트리언의 역할 에 대한 통제방안마련은 지금의 인터넷 공간의 여건에서 필요 한 것이 아닌가 하는 생각이 든다. 그러나 이 또한 형법적 통 제가 아닌 방향으로 이루어지는 것이 바람직할 것이다.

\section{참고문헌}

(1) Christoph Lau, Gesellschaftliche Auseinandersetzungen um Definition von Risiken, Sozial Welt, 1989, S. 418ff.

[2] Claus Roxin, Zur Entwicklung der Kriminalpolitik seit den Alternativ-Entwürfen, JA 1980,S.545ff.

[3] Annual General Assembly Report of the Human Rights Committee, UN Doc. A/50/40, 3 October 1995.

[4] Boyd, D. M. \& Ellison, N. B. (2007). Social Network Sites: Definition, History, and Scholarship. Journal of Computer-Mediated Communication, 13.

[5] Jescheck/Weigend, Lehrbuch des Strafrecht AT. 5. Aufl., 1996.

[6] Lee Jae-Jin, "Internet campaign violated the election law after the transcripts allowed?", media today, 2012.

[7] Christoph Lau, Gesellschaftliche Auseinander -setzungen um Definition von Risiken, Sozial Welt, 1989.

[8] Claus Roxin, Zur Entwicklung der Kriminalpolitik seit den Alternativ-Entwürfen, JA 1980.

[9] Park sang HO, "involved the process of forming public opinion and behavior of the SNS study", the Korean media informatics are of 58 , no. 1 , 2012.

〔10] YLJung, "purpose crime”, Gosigee, 2001/11.

[11] Lee Jae-Jin, "Internet campaign violated the election law after the transcripts allowed?", media today, 2012.

[12] DHKim, "The national security law article 71 and 5 from the interpretation in protest", the criminal case studies I, 1993.

〔13] YSLee, "About the purpose and the intention", Modern judicial, 1996

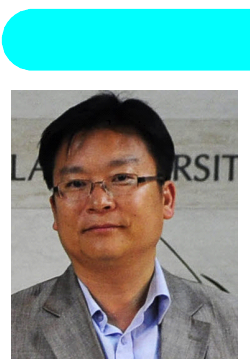

\section{저 자 소 개}

\section{이 주 일}

1989: 한국외국어대학교 법과대학 법학과 법학사.

1996: 한국외국어대학교 일반대학원 법학석사.

2002: 한국외국어대학교 법학과 법학박사

현 재: 신라대학교 법경찰학부 교수 관심분야: 컴퓨터범죄

Email : leejuil@silla.ac.kr 